\title{
The design and implementation of a dynamic news release system based on ASP.NET \\ Shuhong Sun
}

\author{
Changchun Vocational Institute of Technology, Changchun, China \\ sunshuhongcc@126.com
}

Keywords: ASP.Net; B/S; SQL Server; three layer architecture; news release system

\begin{abstract}
Based on ASP.Net technology and SQL Server 2000 database ,Press release management system development of three layer architecture. The paper introduces the ASP.Net technology characteristic, The realization process of system architecture design, function module design and system are introduced in detail. To achieve the dynamic management of website news, causes to the news information management more timely, efficient, improve the work efficiency; improve the safety and reliability of the system, the browsing speed.
\end{abstract}

\section{Introduction}

With the rapid development of network technology and popularity of Internet application, government departments, enterprises and institutions in the establishment and improvement of their own website, the purpose is to carry out its image through the website propaganda, to carry out e-commerce.School construction site is an important aspect of higher education informatization construction, is the important ways to improve the school publicity and exchange and cooperation, can greatly improve the teaching, scientific research, management efficiency. The news as an indispensable site exchange the latest information portal platform, campus news publishing system will need on some Webpage often become more frequent information, such as news, Department notification to update the information centralized management, and classified by some common information, release, finally to a standard system a web site applications. The use of ASP.NET technology can make full use of the program's versatility and portability, and the system similarity, through the comprehensive use of database technology, component

technology, and ultimately achieve timely news release,

the purpose of rapid site generation[1].

\section{Press release system demand analysis}

\section{A. User demand}

Press release system user types mainly include general visitors, administrators,teachers and students in school.

general visitors. In order to understand the college campus news.

$\checkmark$ the administrative personnel. In the school education and teaching, scientific research and other daily administrative function.

the teacher. To understand the latest school teaching, the scientific researchdynamic.

$\checkmark$ the students. Participation in school learning, entertainment activities, understanding the size of the school things.

B. Functional requirements

$\checkmark$ the news release system should be convenient to the campus news publishing, communication and convenient connection between users. 
$\checkmark$ the campus press release system should be reasonable, efficient, trouble freeoperation, and can provide safe, reliable information service for users.

- the campus news publishing system centralized management, timelyuninterrupted operation of monitoring network, quickly find out the fault restoration of network nodes, the user application.

$\checkmark$ the development of campus news publishing system, not only to pay attention tothe necessity and feasibility, to pay attention to the economic effect.

\section{Design of news publishing system}

\section{The architecture of the design system}

The system uses ASP.NET B/S three layer architecture development and design based on. The model realizes the separation of the development environment and application environment, the user terminal with a relatively unified browser instead of the client software, realizes the cross platform application[2]. Based on the ASP.NETB/S three layer architecture is divided into the presentation layer, business logic layer and data layer, system structure as shown in figure 1.

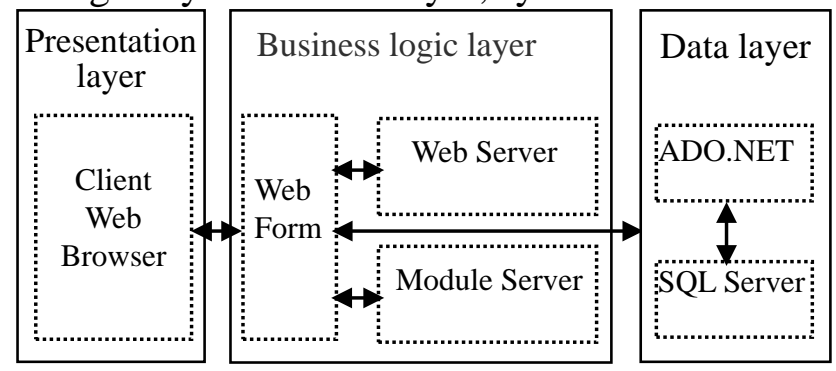

Figure 1. Campus news publishing system structure

D. Design of function and structure of the systems

\begin{tabular}{lll}
\hline The field & Data type & Explain \\
\hline name & Automatic & Classification \\
Class & Numbering & Number \\
Ordered & Character & Category name \\
ArticleNum & Number & Sequence number \\
Parented & Number & The article number \\
PPath & Character & The \\
Child & Number classification \\
CTempId & Number & $\begin{array}{l}\text { Sumb rlassification } \\
\text { Classification } \\
\text { template }\end{array}$ \\
NewsTempID & Number & News template \\
\hline
\end{tabular}

From the design concept, design news release system well embody the people-oriented and to serve as the center concept; from a resource perspective, news website, should make full use of existing resources, integration of teaching, experiment and scientific research aspects of information resources; looking from the function, campus news publishing system plays a publicity school information, the important role of internal convey the spirit of the higher level of[3]. Based on the above analysis, campus news publishing system function design as shown in figure 2. 


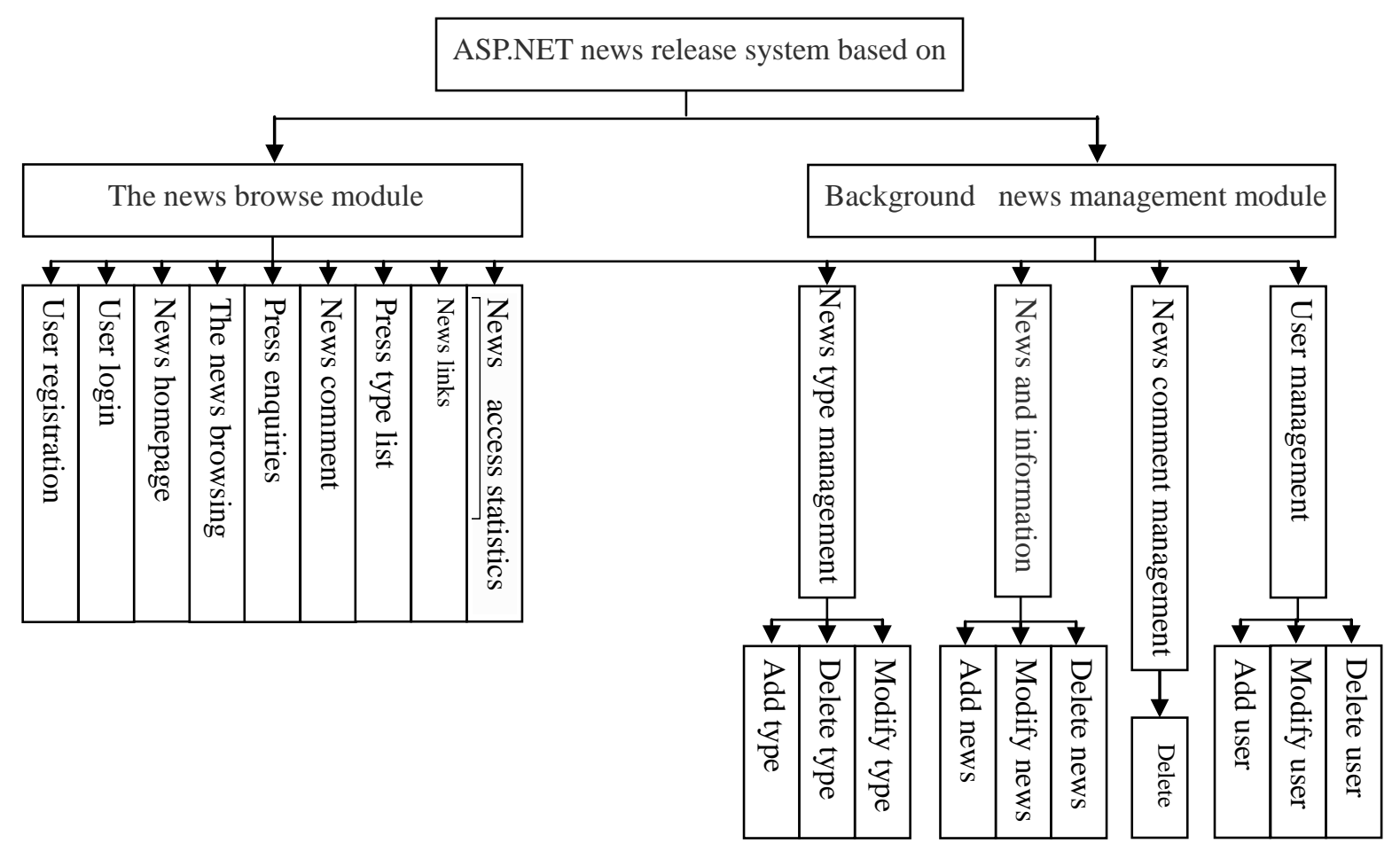

Figure 2. System structure diagram of news publishing system based on ASP.NET

\section{E. System module design}

- The school the important news: comparison of significant news events on campusoccur, including superior leadership to the school inspection and inspection work, the school leaders to participate in a variety of important meetings and activities, the school is responsible for hosting or sponsoring activities, meetings, school important achievements of teaching and scientific research, international cooperation and exchange activities.

- The school daily news: cover a relatively wide range, including the college, the Department of scientific research activities, display and promotion.

- Announcement: school sponsored and scientific research, teaching and student activities related to the lecture notice, the activities of the forum, such as the report.

- Media reports: this section is mainly the social various news media reported thenews, school leaders, teachers and other published important articles in the external media, media on the school, students obtain results reports etc.

- News: including special events such as school, celebration, campus character topic, faculty, student activities such as special topics.

\section{F. Database design system}

News release system database design is the focus of the work on the logic structure design results are optimized and get the data table design, the final design of the table structure as shown in figure 3. Use SQL Server2000 news to establish database, table 1, 2 is one of several important table structure ${ }^{[4]}$. 
TABLE I. COLUMNS IN TABLE

\begin{tabular}{lll}
\hline The field name & Data type & Explain \\
\hline ArticleID & $\begin{array}{l}\text { Automatic } \\
\text { numbering }\end{array}$ & Press number \\
SpecialID & Digital type & Special number \\
Title & Character & Title \\
Author & Character & Author \\
CopyFrom & Character & Source \\
Editor & Character & The editor \\
Hits & Number & The number of clicks \\
UpdateTime & Time & Modified time \\
Hot & Character & Hot spot \\
OnTop & Character & Fixed \\
Content & Text & The news content \\
ClassID & Number & Column number \\
SkinID & Number & Style \\
LayoutID & Number & Template \\
\hline
\end{tabular}

TABLE II. TABLE NEWS

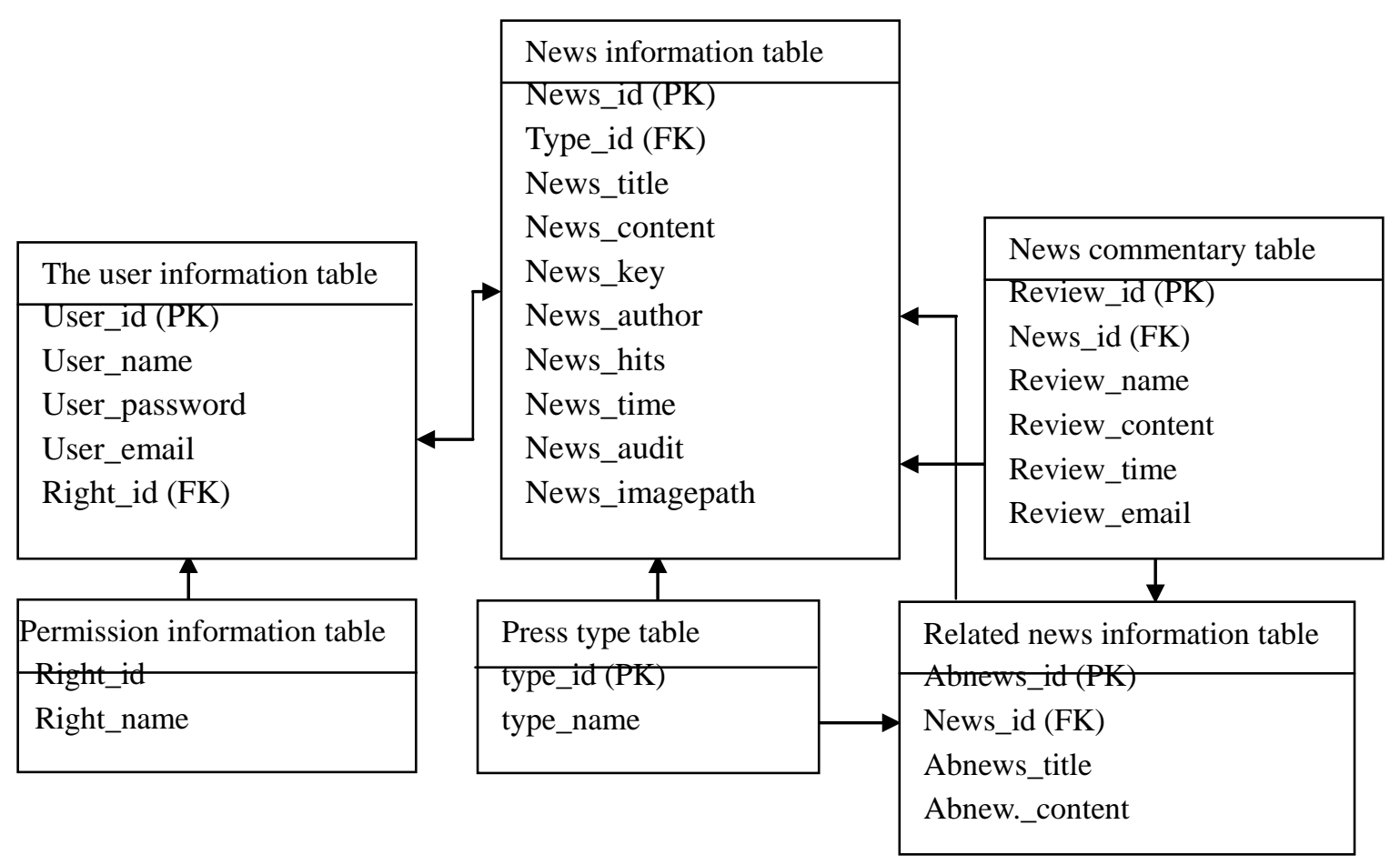

Figure 3. The database table structure diagram

\section{The campus press release management and maintenance system}

\section{G. Hierarchical management.}

Campus news publishing system to take Webpage update, system maintenance, system depth development of three different levels to keep the site safety, efficient, permanent operation. Webpage renewal square and view websites and traditional media, resource sharing, complementary advantages. Set up a press censorship, the network administrator to all-weather monitoring server, maintain system maintenance and data backup every 
day, without loss of data to ensure the system security and hacker attack time. Depth development of the system, the establishment of the management committee by the website, website constructionunit responsible person and related personnel, emergency, determine the contentand form of web plate and concrete channel, guidance, training, management and assessment of the site staff.

H. The establishment of network news center.

The establishment of network news center, integration of newspaper, radio station, newspaper reporter station press corps, ensure access to information can be timely appear in the news website andon page. Campus news website to set up their own specialized team of reporters,school people reported news from the Internet news angle, ensuring Webpageillustrated, audio-visual co-occurrence. Fully mobilize the enthusiasm of College Web site, to ensure sufficient manuscript source[5].

I. Training the network editor.

Campus news website is the product of the combination of network technology andthe ideological and political education. Managers should not only have the computer network of the high technology, but also has high ideological consciousness, policy theory level. To their training, and strive to network editor not only has high ability of computer network technology and the text, images, audio and video processing, but also have high political consciousness, policy theory level, but also can accurately grasp the students' ideological dynamic behavior.

\section{Conclusion}

Each functional module design model and system in this paper, the campus press release system, the realization of the key technology of the system are analyzed in detail, and an effective solution is put forward on the key issues in system design. At the same time, the system uses B/S three layer structure, and make full use of the advantages of ASP.NET2.0 technology, the system has good maintainability and security, to solve the traditional C/S news release the shortcomings of the system safety, provide better service for the campus for the majority of teachers and students, has a certain practicality.

\section{References}

[1] Y. X. Lou, "Design and Implementation of A Network Online Forum System on ASP.NET," Computer Knowledge and Technology, vol. 12, pp.938-969, May 2014.

[2] K. Xiao, "The Design and Implementation of Student Information Management System Based on ASP.NET,” Computer Programming Skills \& Maintenance, vol. 16, pp.33-44, April 2014.

[3] W. J. Tian, “Desing and Implementation of Press Release System Based on ASP.NET,"Digital Technology \& Application, vol. 8, pp.41-42, Feb. 2010

[4] Z. Q. Cai, “Design and implementation of news promulgation system based on .Net,"Computer Engineering and Design, vol. 10, pp.1645-1650, June 2005.

[5] B. Sun, "Design and Realization of Content Manager System Based on ASP.NET," Modern Electronics Technique, vol. 13, pp.102-104, April 2006. 